\title{
Mechanism of triptolide in treating ankylosing spondylitis through the anti-ossification effect of the BMP/Smad signaling pathway
}

\author{
GUILONG WANG ${ }^{1}$, JING CAI ${ }^{2}$, JINSHAN ZHANG ${ }^{3}$ and CUIYUN LI ${ }^{4}$ \\ Departments of ${ }^{1}$ Orthopedics, ${ }^{2}$ Neurosurgery, ${ }^{3}$ Medical lmaging and ${ }^{4}$ Pathology, \\ Linyi People's Hospital, Linyi, Shandong 276000, P.R. China
}

Received August 1, 2016; Accepted July 27, 2017

DOI: $10.3892 / \mathrm{mmr} .2017 .8117$

\begin{abstract}
The present study aimed to examine the mechanism of triptolide in the treatment of ankylosing spondylitis (AS) through the anti-ossification effect of bone morphogenetic protein (BMP)/small mothers against decapentaplegic (Smad) pathway. Male rats were randomly divided into five groups: Normal rat group; model group; triptolide low dose group $(10 \mathrm{mg} / \mathrm{kg})$; triptolide middle dose group $(20 \mathrm{mg} / \mathrm{kg})$; triptolide high dose group (40 mg/kg). The spinal joint capsules of each group of rats were collected to perform primary cell culture to determine the levels of cell proliferation. Western blot and reverse transcription-polymerase chain reaction analyses, and ELISA were used to detect the mRNA and protein expression levels of core-binding factor $\alpha 1$ (Cbfal), BMP receptor type II (BMPRII), Smad1, Smad4, Smad5 and Smad6, the protein expression of phosphorylation indicators, including phosphorylated (p)Smad1 and pSmad5, the mRNA expression of tumor necrosis factor- $\alpha$ (TNF- $\alpha$ ), interleukin (IL)- $1 \beta$ and IL-6 in rat plasma, and the mRNA expression of BMP/Smads in fibroblasts induced by recombinant human (rh)BMP-2. The effects on AS in the rats were also examined. The results revealed that, following intervention with triptolide, inflammation was suppressed, and the mRNA expression levels of TNF- $\alpha$, IL- $1 \beta$ and IL- 6 were reduced. The expression levels of Cbfal, BMPRII, Smad1, Smad4 and Smad5 were also reduced, whereas the expression of Smad6 was increased. Following induction by rhBMP-2, the effects of triptolide weakened, with the most marked effects observed at the highest concentration, suggesting that triptolide functions through the BMP/Smad signaling pathway. Taken together, the results suggested that triptolide may be used to treat AS, the mechanism of which may be through the BMP/Smad pathway.
\end{abstract}

Correspondence to: Mrs. Cuiyun Li, Department of Pathology, Linyi People's Hospital, 27 Jiefang Road, Linyi, Shandong 276000, P.R. China

E-mail: licuiyun058032@163.com

Key words: ankylosing spondylitis, triptolide, phosphorylation, bone morphogenetic protein/small mothers against decapentaplegic signaling pathway

\section{Introduction}

Ankylosing spondylitis (AS) is a common clinical rheumatic disease, which can cause spinal joint stiffness deformity if improperly or untimely treated, with the potential to cause significant pain for patients. As an autoimmune disease, AS can be caused through pathological consequences, including complex immune dysfunction, inflammation, ossification and bone destruction. Therefore, the key to the treatment of AS lies in immune regulation, anti-inflammatory effects, and preventing bone ossification and destruction (1-4). At present, priority is focused on the identification of effective treatment and drugs.

According to traditional Chinese medicine, the key to the treatment of AS is to facilitate blood circulation, combating chill and inflammation, which are the main functions of triptolide, to ease swelling and pain, and to exhibit insecticide and detoxification effects (5). Therefore, there is an adequate theoretical basis to investigate the effects of triptolide on AS. Bone morphogenetic proteins (BMPs) are a family of proteins with multiple biological functions, which can specifically bind to and activate receptors on the membrane of target cells, with small mothers against decapentaplegic (Smad) being the classical pathway of BMP signal transduction (6-8). The molecular basis and mechanism of control of the BMP/Smad pathway has been investigated extensively, and it has been suggested that AS is treated through this pathway. The present study aimed to investigate the effects of triptolide on AS, and whether the treatment occurs through the anti-ossification effect of the BMP/Smad signaling pathway.

\section{Materials and methods}

Establishing the rat AS model. A total of 50 Sprague-Dawley rats (25 female, 25 male; age, 8 weeks; weight, 180-200 g) were obtained from the Animal Center of Sun Yat-Sen University (Guangzhou, China). The rats were kept in an environment at $26^{\circ} \mathrm{C}$ with $55 \%$ humidity, a12-h light/dark cycle and free access to food and water. Each rat was injected subcutaneously, with the exception of rats in the normal group, with $0.2 \mathrm{ml}$ collagen emulsifier 1-2 cm from the tail base, following which a small, white skin rash emerged. The emulsifier contained bovine type II collagen (cat. no. 20032; Chondrex, Redmond, WA, USA) dissolved in $0.05 \mathrm{~mol} / 1$ acetic acid, which was mixed with incomplete Freund's adjuvant (cat. no. 20031; Chondrex) at a ratio of $1: 1$ and density of $2 \mathrm{mg} / \mathrm{ml}$. The mixture was placed in 
an ice-bath until sufficiently emulsified $\left(4^{\circ} \mathrm{C}\right.$ overnight). Of the 50 collagen emulsifier-sensitized rats, 40 showed symptoms of secondary arthritis following immunization. The four limbs of the animals, particularly the hind limbs, exhibited swelling and redness. An increased arthritis index (9) indicated successful model establishment. The experimental rats were divided into five groups with eight animals in each group: Normal group; model group; triptolide low dose group $(10 \mathrm{mg} / \mathrm{kg})$; triptolide middle dose group $(20 \mathrm{mg} / \mathrm{kg})$; triptolide high dose group $(40 \mathrm{mg} / \mathrm{kg})$. The rats were administrated by gavage daily for 30 days following model establishment. The present study was approved by the Ethics Committee of Sun Yat-sen University.

Primary culture of fibroblast cells. The spinal joint capsules were obtained from the rats in all groups, which were placed in $0.1 \%$ benzalkonium bromide for $15 \mathrm{mi}$, and fixed. The capsules were placed into a clean dish and rinsed with PBS, following which adipose tissues were removed, cut into a paste with ophthalmic scissors and transferred into $15 \mathrm{ml}$ centrifuge tubes. To each tube, $0.2 \%$ Type II collagenase was added at 2-3 times the volume of the tissues. Following sufficient agitation, the tubes containing the tissues were placed into a $37^{\circ} \mathrm{C}$ incubator with $5 \% \mathrm{CO}_{2}$ for $2 \mathrm{~h}$. The tissues were then centrifuged at $1,000 \mathrm{xg}$ at $4^{\circ} \mathrm{C}$ for $10 \mathrm{~min}$, and the supernatant was discarded. The tissues were added to DMEM high glucose medium containing $10 \%$ fetal bovine serum (both from Hyclone; GE Healthcare Life Sciences, Logan, UT, USA) and $1 \%$ penicillin-streptomycin to resuspend the cells. The cell density was adjusted to $2 \times 10^{5} / \mathrm{cm}^{2}$. The cells were placed into a $37^{\circ} \mathrm{C}$ incubator with $5 \% \mathrm{CO}_{2}$ overnight, and the non-adherent cells were removed. The medium was replaced once every 3-4 days. The cells were digested and passaged with $0.25 \%$ trypsin. When passaged to the third generation, $>99 \%$ of the cells were identified as fibroblast-like synovial cells. Third generation rat fibroblast-like synovial cells were used in the subsequent experiments.

Detection of cell proliferation using a CKK-8 assay. The spine joint capsule fibroblasts were obtained from well-grown third generation normal rats, and seeded into a 96-well plate at a density of $1 \times 10^{5}$, with $100 \mu l$ in each well. The plate was placed in a $37^{\circ} \mathrm{C}$ incubator with $5 \% \mathrm{CO}_{2}$. Proliferation was detected when adherence was visible, and five wells were assessed once every $24 \mathrm{~h}$. The medium was suctioned out, and replaced with $100 \mu \mathrm{l}$ fetal bovine serum-free DMEM and $10 \mu \mathrm{l}$ CCK- 8 . The fibroblasts were incubated for $40 \mathrm{~min}$, and the absorbance was measured at the wavelength of $450 \mathrm{~nm}$ using an enzyme-linked immunosorbent detector. When the cells were at the plateau stage, the proliferation of the AS spine joint capsule fibroblasts were measured.

Determination of rat plasma levels of TNF- $\alpha, I L-1 \beta$ and $I L-6$. According to the manufacturer's protocol, Boster sandwich ELISA kits (TNF- $\alpha$, cat. no. 050102-RT; IL-1 $\beta$, cat. no. 070015-D; IL-6, cat. no. 012043-M) from Beijing Saichi Biotechnology Co., Ltd. (Beijing, China) were used with the following steps: $0.1 \mathrm{ml}$ plasma was added to the 96 -well plate with the primary antibody (TNF- $\alpha$, IL- $1 \beta$ and IL-6), with sample dilution only added to the zero hole. The plate was covered with a microtiter plate and incubated at $37^{\circ} \mathrm{C}$ for $1.5 \mathrm{~h}$. The liquid in the microtiter plate was discarded following incubation, and $0.1 \mathrm{ml}$ antibody solution (TNF- $\alpha$, cat. no. sc-52011; IL-1 $\beta$, cat. no. sc-52022; IL-6, cat. no. sc-52003) from Santa Cruz Biotechnology, Inc. (Dallas, TX, USA) was added to each well prior to incubation at $37^{\circ} \mathrm{C}$ for $1 \mathrm{~h}$. Again, the liquid in the microtiter was removed, and the plate was rinsed with PBS three times. To each well, $0.1 \mathrm{ml} \mathrm{ABC}$ working solution was added and incubated at $37^{\circ} \mathrm{C}$ for $30 \mathrm{~min}$. The liquid in the microtiter was discarded following incubation and the plate was rinsed with PBS three times. Subsequently, $90 \mu 1$ TMB color reagent was added to each well, which was pre-balanced at $37^{\circ} \mathrm{C}$ for $30 \mathrm{~min}$ and then incubated at $37^{\circ} \mathrm{C}$ in the dark for $30 \mathrm{~min}$. The optimal coloration time point was determined when the first 3rd-4th standard well exhibited gradient blue, and when no significant difference was observed in the last 3rd-4th well. To each well, $0.1 \mathrm{ml} \mathrm{TMB}$ stop solution was added, and the liquid in the microplate turned from blue to yellow. The optical density (OD) value at a wavelength $450 \mathrm{~nm}$ was measured using a microplate reader.

Detection of the $m R N A$ expression levels of core-binding factor al (Cbfal), BMPRII, Smad1, Smad4, Smad5, and Smad6 in synovial tissues using reverse transcription-polymerase chain reaction (RT-PCR) analysis. The rat knee synovial tissues were obtained and added to TRIzol reagent (BD Biosciences, Franklin Lakes, NJ, USA) for sufficient lysis. The tissues were added to $0.2 \mathrm{ml}$ chloroform, agitated, and placed standing in an ice bath for $5 \mathrm{~min}$. The tissues were then centrifuged (Heraeus AG, Hanau, Germany) at $1,611 \times \mathrm{g}$ at $4^{\circ} \mathrm{C}$ for $20 \mathrm{~min}$. The supernatant was discarded and replaced with an equal volume of isopropanol. After 5 min standing in an ice bath, the tissues were centrifuged at $1,119 \mathrm{x} \mathrm{g}$ at $4^{\circ} \mathrm{C}$ for $20 \mathrm{~min}$. The supernatant was discarded and replaced with $1 \mathrm{ml} 75 \%$ ethanol. The tissues were centrifuged at $1,119 \mathrm{x} \mathrm{g}$ at $4^{\circ} \mathrm{C}$ for $5 \mathrm{~min}$. The supernatant was carefully removed. The EP tube was turned upside down, and dried under room temperature for $15 \mathrm{~min}$, and $20 \mu \mathrm{l}$ RNase-Free $\mathrm{ddH}_{2} \mathrm{O}$ was added to the dried pellet to dissolve the precipitate. Subsequently, $1 \mu 1$ liquid was drawn into an Eppendorf tube, and the remainder was stored in a $-70^{\circ} \mathrm{C}$ refrigerator. The 1- $\mu \mathrm{l}$ solution was diluted to $80 \mu \mathrm{l}$ with $\mathrm{ddH}_{2} \mathrm{O}$. The OD 260 and OD 280 values were measured on a spectrophotometer (Eppendorf, Hamburg, Germany) and the total RNA was calculated. cDNA synthesis and the reverse transcription experiment were performed using the PrimeScript RT reagent kit (cat. no. DRR031; Sigma-Aldrich; Merck Millipore, Darmstadt, Germany) according to the manufacturer's protocol. The reaction sample contained 12.5 $\mu 1$ SYBR Premix Ex Taq, $1 \mu$ l PCR forward primer, $1 \mu 1$

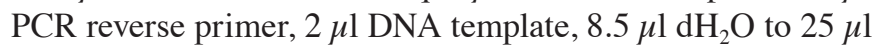
total. The RT-PCR steps were as follows: Amplification profile, initial denaturation at $95^{\circ} \mathrm{C}$ for $5 \mathrm{~min}$, denaturation at $95^{\circ} \mathrm{C}$ for $20 \mathrm{sec}$, annealing at $60^{\circ} \mathrm{C}$ for $30 \mathrm{sec}$, and extension at $72^{\circ} \mathrm{C}$ for $20 \mathrm{sec}$ for fluorescence signal acquisition (40 cycles in total). The dissolution profile was $60-95^{\circ} \mathrm{C}$, with $0.5^{\circ} \mathrm{C}$ per increment, maintained for $20 \mathrm{sec}$ and with 71 cycles in total, this stage was for fluorescence signal acquisition. In order to verify the size of the PCR products, $10 \mu \mathrm{l}$ solution was collected for electrophoresis on a $1 \%$ agarose gel. Quantification was performed as previously described (10). The primer sequences were as follows: Cbfal, forward 5'-TCGGATTATGCAGCAGTTGCC T-3' and reverse 5'-ACTGCCATCCTGATCCACGCTC-3'; 


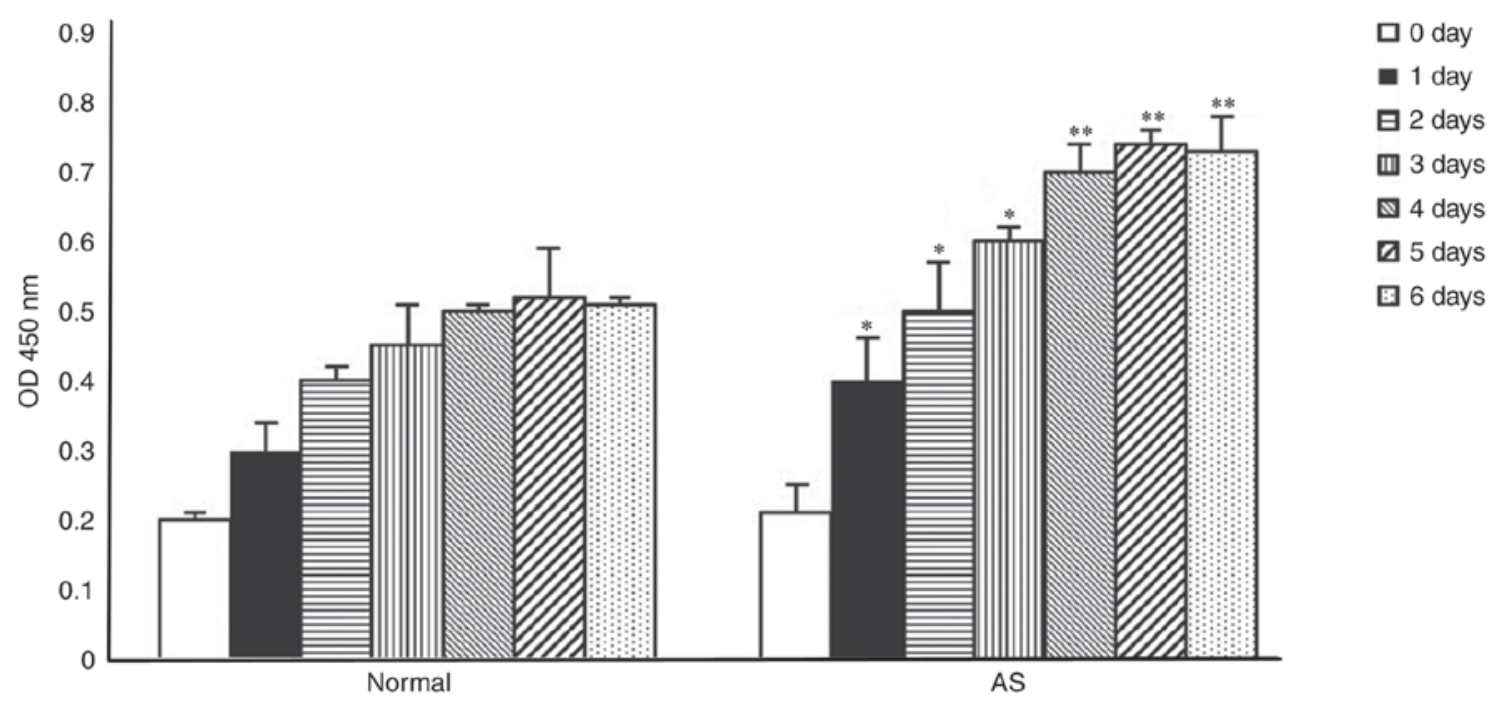

Figure 1. Fibroblast proliferation without treatment. ${ }^{* *} \mathrm{P}<0.01$, vs. normal group; ${ }^{*} \mathrm{P}<0.05$, vs. normal group. AS, ankylosing spondylitis; OD, optical density.

BMPRII, forward 5'-GTGCAGACGAGTTGCCAGACTT-3' and reverse 5'-GGCACGCCTATGACGGTATTTC-3'; Smadl, forward 5'-TAGCAGAGCAGATGCCCAGGTT-3' and reverse 5'-CGCACGAAGATGTTACTGTCTT-3'; Smad4, forward 5'-AGCAGAGGAGAGGTTCATCTG-3' and reverse 5'-CGG ACCCCGTTGCTGGTGTTTAG-3'; Smad5, forward 5'-CAG CACACCACTTGTTCAGTCT-3' and reverse 5'-GGTTCG ATGATCCTGCTGTAAC-3'; Smad6, forward 5'-CGTAAG ATGAGTTGTTCAGATT-3' and reverse 5'-CCTACGTTG ATGGTGGTATCAT-3'; TNF-a, forward 5'-CGTTCGGTC GCAACAACCT-3' and reverse 5'-CGTTTGGTCGTTTGC TACATA-3'; IL-1 $\beta$, forward 5'-CGTGATGTACCAGTTGGG T-3' and reverse 5'-GTCCATGAGCTTTGTACTACT-3'; IL-6, forward 5'-GCGCTTCACGAACACCCATG-3' and reverse 5'-GGGAATTGCCATTGCACGGTGG-3'; GAPDH, forward 5'-TTACTGGTCGTGGACGGCCAT-3' and reverse 5'-AAA CGGACACTCACAATGGGCC-3'.

Detection of the protein expression levels of Cbfal, BMPRII, Smad1, Smad4, Smad5 and Smad6 using western blot analysis. The fibroblast-like synovial cells were collected from all rats and washed twice with PBS. To each flask, $400 \mu \mathrm{l}$ lysate was added, followed by $40 \mu \mathrm{l}$ PMSF at a concentration of $10 \mathrm{mmol} / \mathrm{l}$. The flasks were agitated gently, and placed on ice for $10 \mathrm{~min}$ to lyse the cells uniformly. The cells were repeatedly drawn with a sterile syringe and the lysate was added to an EP tube, which was then placed in an ice bath for $30 \mathrm{~min}$ and centrifuged at $1,611 \times \mathrm{g}$ at $4^{\circ} \mathrm{C}$ for $15 \mathrm{~min}$. The supernatant was moved to a new EP tube, and protein density was measured on a microplate reader and using BCA assay. To each tube, $20 \mu \mathrm{l}$ $6 \mathrm{X}$ buffer was added for every $100 \mu \mathrm{l}$, followed by boiling for $5 \mathrm{~min}$, mixing and storing at $-80^{\circ} \mathrm{C}$. These samples $(20 \mu \mathrm{g})$ were used for electrophoresis $(\mu 1)$ on a $12 \%$ SDS-PAGE gel. The isolated protein bands were then transferred onto a PVDF membrane using a wet method, and subsequently maintained at room temperature for $1 \mathrm{~h}$. The membrane was then incubated with primary antibodies: Cbfal (cat. no. IBSBIOA-1; Sigma-Aldrich; Merck Millipore), BMPRII (cat. no. PA130036; Sigma-Aldrich; Merck Millipore), Smad1 (cat. no. sc-1612; Santa-Cruz Biotechnology, Inc., Dallas, TX, USA), Smad4 (cat. no. sc-0598; Santa-Cruz Biotechnology, Inc.), Smad5 (cat. no. sc-26412; Santa-Cruz Biotechnology, Inc.), and Smad6 (cat. no. sc-1304; Santa-Cruz Biotechnology, Inc.). The dilution for all antibodies was 1:1,000. The membrane was incubated overnight under $4^{\circ} \mathrm{C}$ and washed with PBST three times. Following this, the membrane was incubated with secondary antibody (cat. no. 563-1; Shanghai Zemai Biotech Co., Ltd., Shanghai, China) at a dilution of 1:1,000 for $1 \mathrm{~h}$ at $4^{\circ} \mathrm{C}$, and washed with PBST three times. Color development and fixing were completed using a chemiluminescence assay. The protein expression levels of Cbfal, BMPRII, Smad1, Smad4, Smad5, and Smad6 were assessed using Image J version 1.48U (National Institutes of Health, Bethesda, MD, USA).

mRNA expression of the BMP/Smad signaling pathway in fibroblasts induced by rhBMP-2. The normal and AS fibroblasts in the third passage logarithmic phase were made into single cell suspensions and seeded into a 24-well plate at a density of $2 \times 10^{7} /$ well. The normal and AS fibroblasts were divided into six groups respectively, and $200 \mathrm{pg} / \mathrm{ml} \mathrm{rhBMP}-2$ was added to each well, with four duplicate wells for each group. The seeded cells were placed in a $\mathrm{CO}_{2}$ incubator overnight for complete cell adherence, following which the supernatant was discarded. The cells in the normal and AS groups were added to $2 \mathrm{ml}$ DMEM containing 10\% FBS and the cells in the remaining group were added to $2 \mathrm{ml}$ DMEM containing rhBMP-2 and 10\% FBS. All groups were placed into a $\mathrm{CO}_{2}$ incubator for $72 \mathrm{~h}$. The contents were obtained to measure the mRNA expression levels of Cbfal, BMPRII, Smad1, Smad4, Smad5 and Smad6.

Statistical analysis. Each experiment was repeated three times. One-way analysis of variance and the Bonferroni test were performed using SPSS version 13.0 (SPSS, Inc., Chicago, IL, USA) for pairwise comparisons in multiple samples. $\mathrm{P}<0.05$ was considered to indicate a statistically significant difference. 


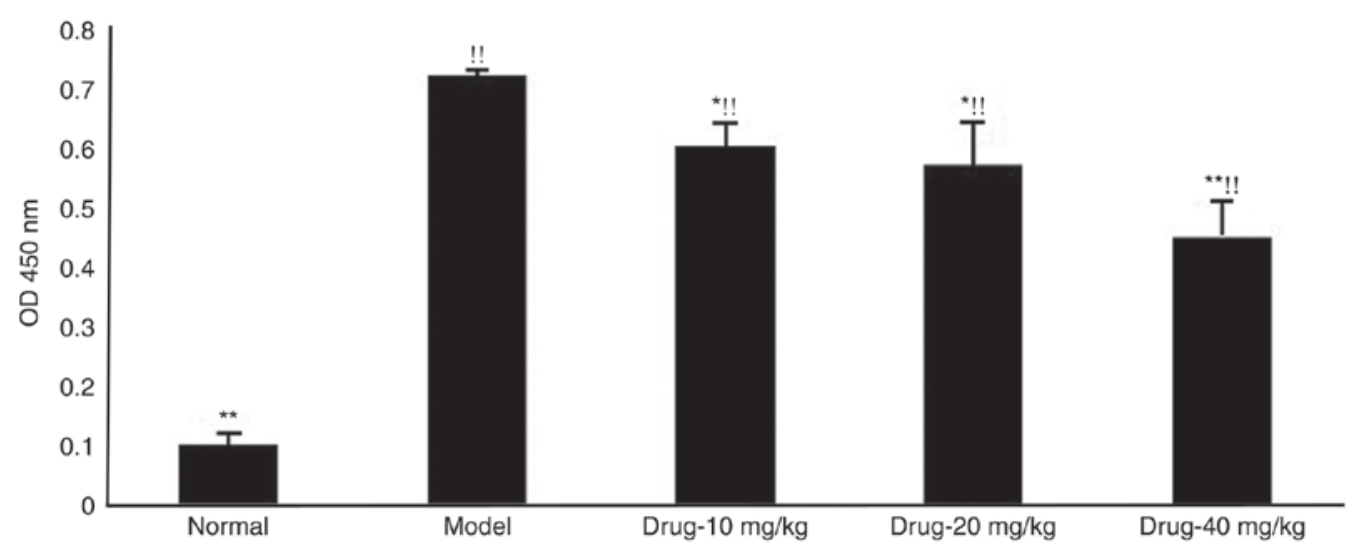

Figure 2. Effect of triptolide on fibroblast proliferation. ${ }^{* *} \mathrm{P}<0.01$, vs. model group; $\mathrm{P}<0.05$, vs. model group; " $\mathrm{P}<0.01$, vs. normal group. OD, optical density; d, day.
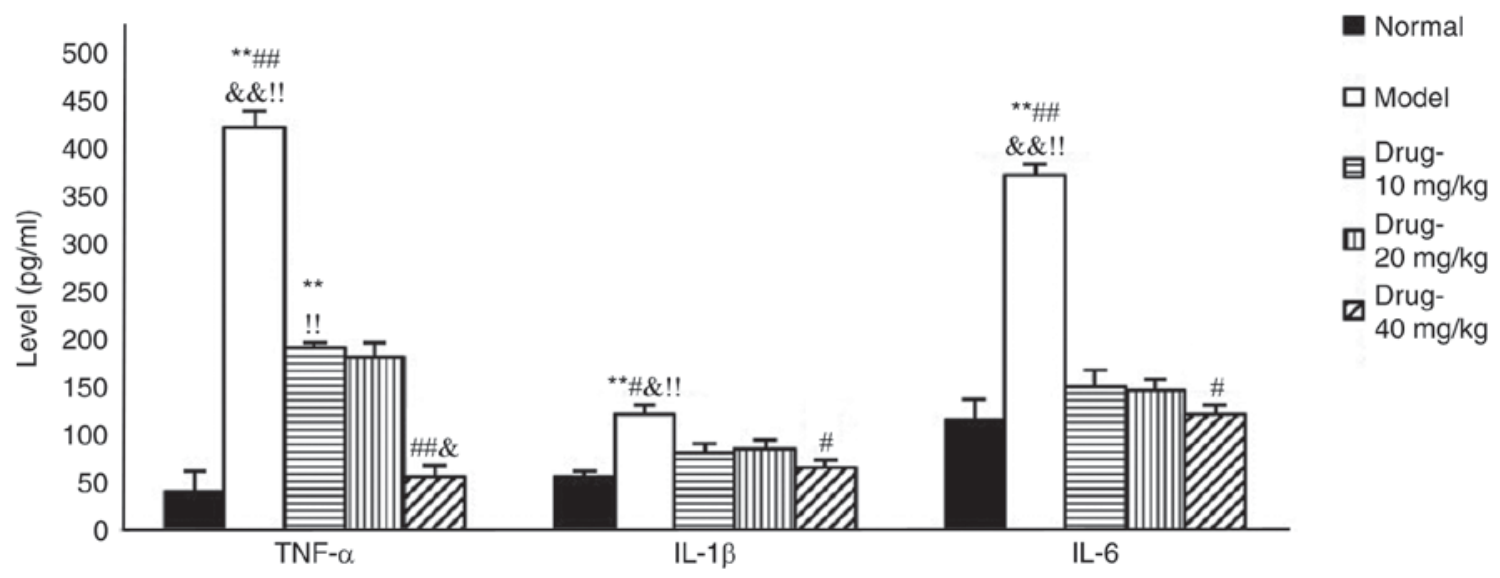

Figure 3. Effects of triptolide on the levels of TNF- $\alpha$, IL- $1 \beta$ and IL-6. ${ }^{* *} \mathrm{P}<0.01$, vs. normal group; ${ }^{*} \mathrm{P}<0.05$, vs. normal group; ${ }^{\# \#} \mathrm{P}<0.01$, vs. drug- $10 \mathrm{mg} / \mathrm{kg}$ group; ${ }^{*} \mathrm{P}<0.05$, vs. drug-10 mg/kg group; ${ }^{\&}{ }^{\circledR} \mathrm{P}<0.01$, vs. drug- $20 \mathrm{mg} / \mathrm{kg}$ group; ${ }^{\mathrm{P}} \mathrm{P}<0.05$, vs. drug $-20 \mathrm{mg} / \mathrm{kg}$ group. TNF- $\alpha$, tumor necrosis factor- $\alpha$; IL, interleukin.

\section{Results}

Proliferation of fibroblast cells. Compared with the normal fibroblasts, the growth rate of the AS fibroblasts was significantly higher following cell adherence for $24 \mathrm{~h}$. The significant difference remained for 6 days $(\mathrm{P}<0.01)$. On day 4 , the proliferation of the normal and AS fibroblasts reached a zenith and entered into the plateau phase (Fig. 1). Intervention with triptolide at this phase showed that triptolide effectively inhibited the proliferation of AS fibroblasts, with the highest concentration resulting in the most marked effect (Fig. 2).

Effects of triptolide on the levels of TNF- $\alpha, I L-1 \beta$ and $I L-6$. The ELISA results showed that, compared with the normal group, the AS spinal arthritis model rats exhibited significantly higher expression levels of TNF- $\alpha$, IL-1 $\beta$ and IL-6. After intervention with triptolide, the TNF- $\alpha$, IL-1 $\beta$ and IL-6 levels were reduced, especially in the high concentration group $(\mathrm{P}<0.01)$. This suggested that combined medication improved the inflammatory response (Fig. 3).

Expression levels of BMPRII and Cbfal. The expression of BMPRII was higher in the AS fibroblasts and was reduced by triptolide, with the most marked effect in the highest concentration group. Cbfal was also expressed at a higher level in the AS fibroblast group, compared with the significantly lower level in the normal fibroblast group. The levels of both were decreased following treatment with triptolide (Fig. 4).

Phosphorylation of pSmadl and pSmad5. pSmad1 and pSmad5 were expressed in the normal and AS fibroblasts, with higher levels in the AS fibroblasts, compared with those in the normal fibroblasts. The degrees of pSmad1 and pSmad5 phosphorylation were significantly decreased following treatment with triptolide (Fig. 5).

Effects of triptolide on the protein and mRNA expression levels of Smad1, Smad4, Smad5 and Smad6. The mRNA and protein expression levels of Smad1, Smad4 and Smad5 in the AS fibroblasts were significantly higher, compared with those in the normal fibroblasts $(\mathrm{P}<0.01)$. These levels were decreased following triptolide treatment, with the most marked effects in the highest concentration group $(\mathrm{P}<0.05)$. However, the mRNA and protein expression levels of Smad6 were lower in the AS fibroblasts, compared with those in the normal group $(\mathrm{P}<0.01)$, although the level increased following triptolide treatment $(\mathrm{P}<0.05$; Figs. 6 and 7$)$. 


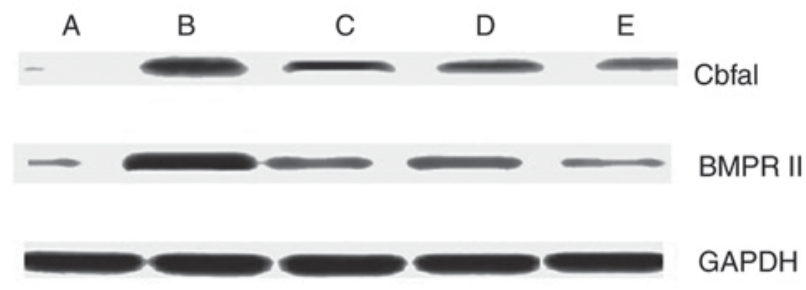

Figure 4. Effects of triptolide on the expression of BMPRII and Cbfal. A, normal group; B, model group; C, drug-10 mg/kg group; D, drug- $20 \mathrm{mg} / \mathrm{kg}$ group; E, drug- $40 \mathrm{mg} / \mathrm{kg}$ group. BMPRII, bone morphogenetic protein receptor type II; Cbfa1, core-binding factor $\alpha 1$.

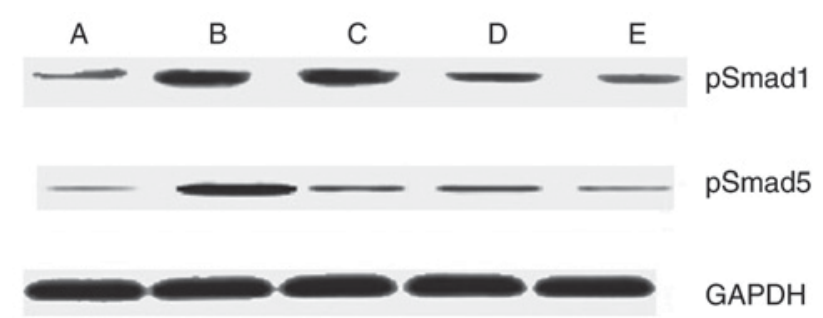

Figure 5. Effects of triptolide on the expression of pSmad1 and pSmad5A, normal; group; B, model group; C, drug-10 mg/kg group; D, drug-20 mg/kg group; E, drug-40 mg/kg group. Smad, small mothers against decapentaplegic; pSmad, phosphorylated Smad.

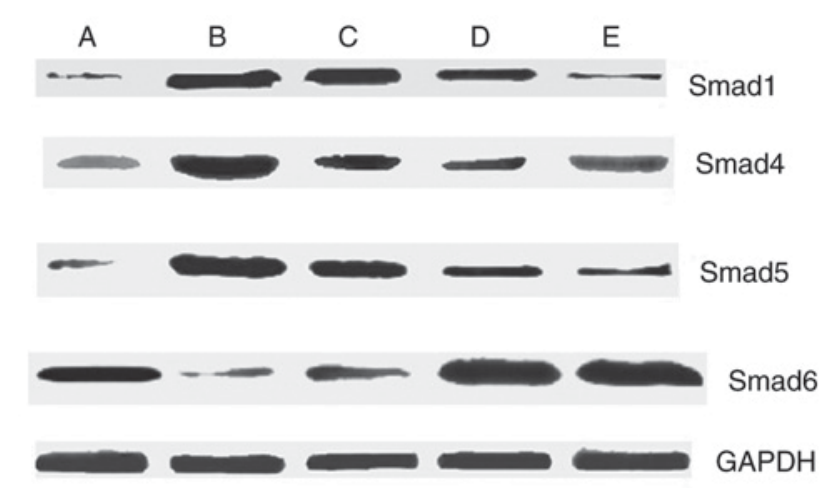

Figure 6. Effects of triptolide on the protein expression of Smad1, Smad4, Smad5 and Smad6. A, normal group; B, model group; C, drug-10 mg/kg group; $\mathrm{D}$, drug-20 mg/kg group; E, drug-40 mg/kg group. Smad, small mothers against decapentaplegic.

mRNA expression levels of Smad1, Smad4, Smad5, Smad6, BMPRII and Cbfal in AS fibroblasts are induced by rhBMP-2. The phosphorylation of Smad1, Smad4, Smad5, Smad6, BMPRII and Cbfal were increased in the AS fibroblasts induced by rhBMP-2, but were decreased following triptolide treatment. This decrease resulted in lower levels, compared with those in the group without exposure to rhBMP-2, suggesting that treatment may function through the BMP/Smad signaling pathway (Fig. 8).

\section{Discussion}

In AS, heterotopic ossification takes place in the spine and peripheral joints, which is a pathological atypical bone formation predominantly occurring in muscle or connective tissues.
Studies have shown that there are three essential conditions for the formation of heterotopic ossification: Precursor cells, an osteogenic inducer, and bone tissue environment. Caused by an initial stimulus, the signal produced in the damaged region requires non-differentiated mesenchymal cells and an appropriate tissue environment to facilitate the formation of heterotopic ossification $(11,12)$. The formation of AS heterotopic ossification is likely to be derived from a change in the differentiation direction of mesenchymal cells in soft tissues. The final formation of ossification is induced by certain osteogenic factors.

BMPs are a family of $>20$ types of glycoprotein isolated and purified from bone matrix, which can regulate the growth and differentiation of various cell types, including stimulating chondrocyte matrix synthesis, increasing osteoblast alkaline phosphatase activity, and facilitating collagen synthesis, nerve cell differentiation and kidney development. BMPs are important in inducing bone and cartilage formation, embryonic development, and organ formation (13). BMP receptors include type I and type II receptors. The type II receptor is structurally active, which is activated through binding with a ligand to induce auto-phosphorylation, through which the activated type II receptor activates the type I receptor, forming a complex receptor and completing BMP activation $(14,15)$.

The binding of BMP ligand with heterologous dimers can activate the Smad-dependent BMP signaling pathway. The Smad family is widespread and can be divided into three types according to their functions in signal transduction. Firstly, the receptor-modulating type includes Smad1, Smad2, Smad3, Smad5 and Smad8, in which Smad1, Smad5 and Smad8 are involved in the signal transduction of BMP, whereas Smad2 and Smad3 are involved in Activin and TGF. Secondly, the common media type comprises Smad4 only and cannot interact with type I receptor or be phosphorylated, but can hybridize with receptor-modulating type Smads to form stable polymers. Thirdly, the inhibitory Smads, comprising Smad6 and Smad7, have a negative effect in the Smad signal transduction pathway through inhibiting receptor-mediated R-Smad carbonation or interfering with the binding of R-Smad and Co-Smad (16,17).

The Smad-dependent pathway is the classic pathway of BMP signal transduction. The $\mathrm{BMP} / \mathrm{Smad}$ pathway is composed of a BMP signal, BMP receptor, and receptor substrate Smad signaling molecules (18). The BMP ligand acts on the membrane type II receptor, the auto-phosphorylation of which causes activation and subsequent phosphorylation of type I receptor; this forms heterogenic polymer complexes, which phosphorylate Smad1, Smad5 and Smad8, thus transducing signals to cells $(19,20)$. The activated R-Smad and Smad4 then bind in the cytoplasm, forming an R-Smad/Smad4 complex, which carries signals to the nucleus and binds with the target gene, activating target gene transcription and transducing signals (21).

In the present study, it was found that the protein and mRNA expression levels of Smad1, Smad4, Smad5, BMPRII and Cbfal in the AS fibroblasts were higher, compared with those in the normal group. The levels of both were decreased by triptolide intervention. BMPRII was inhibited, which was the initiating step of signal transduction, and the subsequent BMP 


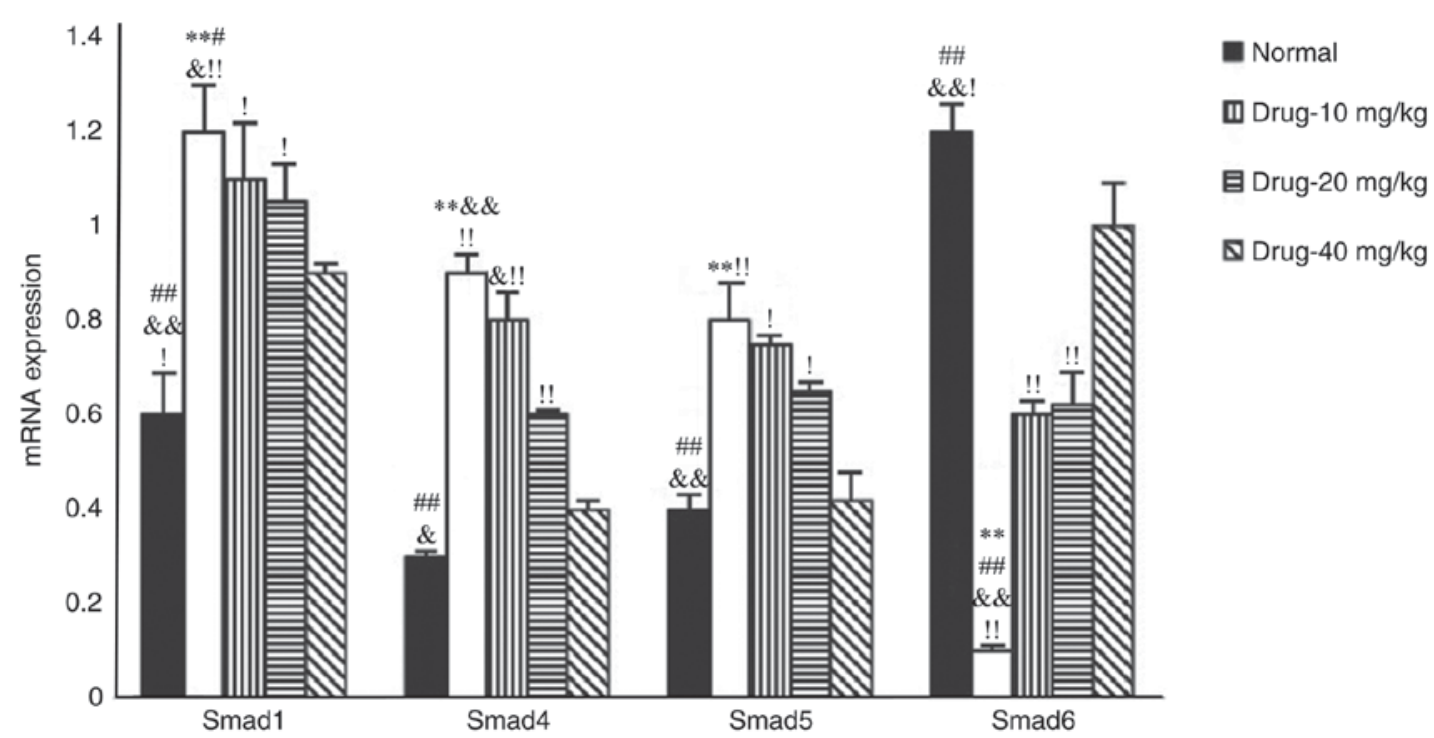

Figure 7. Effects of triptolide on the mRNA expression of Smad1, Smad4, Smad 5 and Smad6. ${ }^{* *} \mathrm{P}<0.01$, vs. normal group; ${ }^{\# /} \mathrm{P}<0.01$, vs. drug-10 mg/kg group;

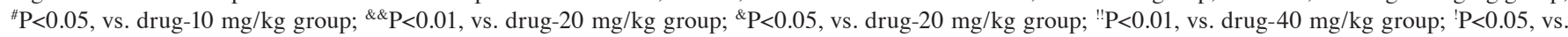
drug- $40 \mathrm{mg} / \mathrm{kg}$ group. Smad, small mothers against decapentaplegic.

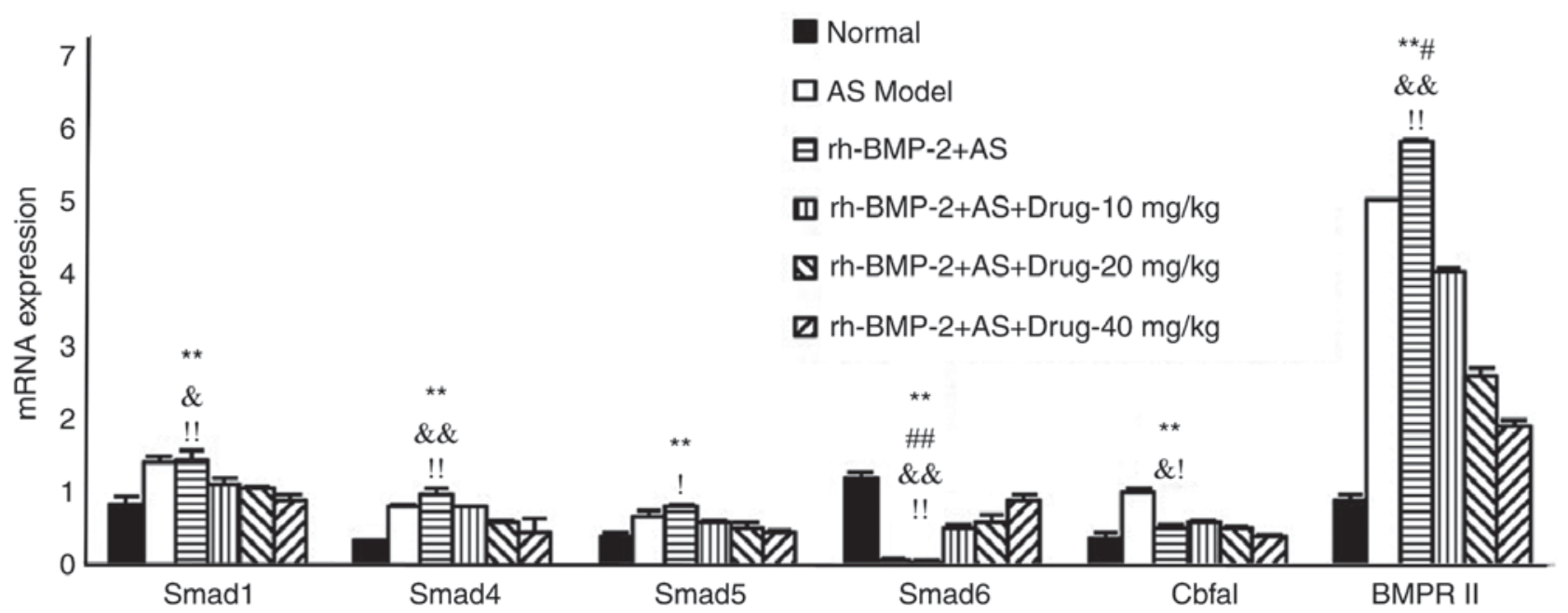

Figure 8. mRNA expression of Smad1, Smad4, Smad5, Smad6, BMPRII and Cbfal in AS fibroblasts induced by rhBMP-2. ** $<<0.01$, vs. normal group;

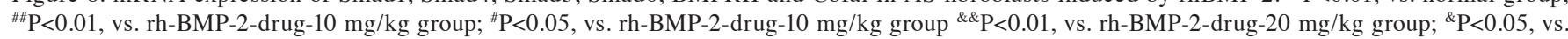
rh-BMP-2-drug-20 mg/kg group; "P $<0.01$, vs. rh-BMP-2-drug-40 mg/kg group; ' $\mathrm{P}<0.05$, vs. rh-BMP-2-drug-40 mg/kg group. AS, ankylosing spondylitis; Smad, small mothers against decapentaplegic; BMPRII, bone morphogenetic protein receptor type II; Cbfa1, core-binding factor $\alpha 1$; rh-BMP, recombinant human BMP.

signal transduction was inhibited. The receptor-modulating receptor Smad was combined into a stable hybrid, and the signal was transduced to the nucleus. The reduction of Smad affected BMP signal transduction, which was most marked in the combined treatment group.

The protein and mRNA expression levels of Smad6 in the AS fibroblasts were lower, compared with those in the normal group, whereas triptolide reversed this effect. Smad6 can regulate BMP signal transduction through multiple pathways. The decrease of type II receptors, Smad1, Smad4, Smad5 and BMPRII was inhibited by combined treatment, as was the phosphorylation of Smad1 and Smad5. The levels of Smad6 were increased and the osteogenic differentiation of AS fibroblasts was inhibited, thus exerting an anti-ossification effect.
Studies have shown that BMP can enhance the expression of Cbfal. BMP-induced osteogenesis is mediated by Cbfal, and BMP is necessary for Cbfal transcript initiation $(22,23)$. The expression of Cbfal in the AS fibroblasts was increased, but decreased following triptolide treatment, with the most marked effect in the combined medication group. This suggested that treatment inhibited the expression of Cbfal or that triptolide inhibited the osteoblastic differentiation of AS fibroblasts.

In conclusion, triptolide inhibited the expression levels of BMPRII and Smad1, increased the expression of Smad6, decreased the phosphorylation of Smad1 and Smad5, regulated BMP/Smad signal transduction, and reduced downstream BMP signaling, thus inhibiting the expression of Cbfal. Triptolide 
may be useful in the treatment of AS, the mechanism of which may occur via the BMP/Smad pathway.

\section{References}

1. Meyer K, Niedermann K, Tschopp A and Klipstein A: Is the work ability index useful to evaluate absence days in ankylosing spondylitis patients? A cross-sectional study. BMJ Open 3: pii: e002231, 2013

2. Gerdan V, Akar S, Solmaz D, Pehlivan Y, Onat AM, Kisacik B, Sayarlioglu M, Erhan C, Tezcan ME, Ozturk MA, et al: Initial diagnosis of lumbar disc herniation is associated with a delay in diagnosis of ankylosing spondylitis. J Rheumatol 39: 1996-1999, 2012.

3. van den Berg R and van der Heijde DM: How should we diagnose spondyloarthritis according to the ASAS classification criteria: A guide for practicing physicians. Pol Arch Med Wewn 120: 452-457, 2010

4. Arends S, Brouwer E, van der Veer E, Groen H, Leijsma MK, Houtman PM, Th A Jansen TL, Kallenberg CG and Spoorenberg A: Baseline predictors of response and discontinuation of tumor necrosis factor-alpha blocking therapy in ankylosing spondylitis: A prospective longitudinal observational cohort study. Arthritis Res Tlier 13: R94, 2011.

5. Bao J and Dai SM: A Chinese herb Tripterygium wilfordii Hook F in the treatment of rheumatoid arthritis: Mechanism, efficacy, and safety. Rheumatol Int 31: 1123-1129, 2011)

6. Qin W, Yang F, Deng R, Li D, Song Z, Tian Y, Wang R, Ling J and Lin Z: Smad 1/5 is involved in bone morphogenetic protein-2-induced odontoblastic differentiation in human dental pulp cells. J Endod 38: 66-71, 2012.

7. ecalco-Cruz AC, Sosa-Garrocho M, Vázquez-Victorio G, Ortiz-García L, Domínguez-Hüttinger E and Macías-Silva M: Transforming growth factor- $\beta /$ SMAD Target gene SKIL is negatively regulated by the transcriptional cofactor complex SNON-SMAD4. J Biol Chem 287: 26764-26776, 2012.

8. Kokabu S, Ohte S, Sasanuma H, Shin M, Yoneyama K, Murata E, Kanomata K, Nojima J, Ono Y, Yoda T, et al: Suppression of BMP-Smad signaling axis-induced osteoblastic differentiation by small C-terminal domain phosphatase 1, a Smad phosphatase. Mol Endocrinol 25: 474-481, 2011

9. Poddubnyy D, Rudwaleit M, Haibel H, Listing J, Märker-Hermann E, Zeidler H, Braun J and Sieper J: Effect of non-steroidal anti-inflammatory drags on radiographic spinal progression in patients with axial spondyloarthritis: Results from the German Spondyloarthritis Inception Cohort. Ann Rheum Dis 71: 1616-1622, 2012.
10. Yi JF and Tang XL: The effect of paeoniflorin, collagen, hypothalamus pituitary kidney in rats with collagen induced arthritis. China Adrenal Axis J Pharmacol Toxicol 27: 668-672, 2013.

11. Wang J: Experimental study of recombinant expression and anti-tumor effect of ING4 gene (unpublished PhD thesis). Soochow University, 2005.

12. Kroon F, Landewé R, Dougados M and van der Heijde D: Continuous NSAID use reverts the effects of inflammation on radiographic progression in patients with ankylosing spondylitis. Ann Rheum Dis 71: 1623-1629, 2012.

13. Ikushima $\mathrm{H}$ and Miyazono $\mathrm{K}$ : TGF- $\beta$ signal transduction spreading to a wider field: A broad variety of mechanisms for context-dependent effects of TGF- $\beta$. Cell Tissue Res 347: 37-49, 2012.

14. Thatcher JD: The TGF-beta signal transduction pathway. Sci Signal 3: tr4, 2010

15. Song B, Estrada KD and Lyons KM: Smad signaling in skeletal development and regeneration. Cytokine Growth Factor Rev 20: 379-388, 2009.

16. Ekman M, Mu Y, Lee SY, Edlund S, Kozakai T, Thakur N, Tran H, Qian J, Groeden J, Heldin CH and Landström M: APC and Smad7 link TGF $\beta$ type I receptors to the microtubule system to promote cell migration. Mol Biol Cell 23: 2109-2121, 2012.

17. Vardouli L, Vasilaki E, Papadimitriou E, Kardassis D and Stournaras C: A novel mechanism of TGFbeta-induced actin reorganization mediated by Smad proteins and Rho GTPases. FEBS J 275: 4074-4087, 2008.

18. Edlund S, Landström M, Heldin CH and Aspenström P: Smad7 is required for TGF-beta-induced activation of the small GTPase Cdc42. J Cell Sci 117: 1835-1847, 2004.

19. Konstantinidis G, Moustakas A and Stournaras C: Regulation of myosin light chain function by BMP signaling controls actin cytoskeleton remodeling. Cell Physiol Biochem 28: 1031-1044, 2011.

20. Chen $G$, Deng $C$ and Li YP: TGF- $\beta$ and BMP signaling in osteoblast differentiation and bone formation. Int J Biol Sci 8: 272-288, 2012

21. Jun JH, Yoon WJ, Seo SB, Woo KM, Kim GS, Ryoo HM and Baek JH: BMP2-activated Erk/MAP kinase stabilizes Runx2 by increasing p300 levels and histone acetyltransferase activity. J Biol Chem 285: 36410-36419, 2010.

22. Huang Q, Zhang H, Pei FX, Chen ZY, Wang GL, Shen B, Yang J, Zhou ZK and Kong QQ: Use of small interfering ribonucleic acids to inhibit the adipogenic effect of alcohol on human bone marrow-derived mesenchymal cells. Int Orthop 34: 1059-1068, 2010.

23. Shi XM, Blair HC, Yang X, McDonald JM and Cao X: Tandem repeat of C/EBP binding sites mediates PPAR gamma2 gene transcription in glucocorticoid-induced adipocyte differentiation. J Cell Biochem 76: 518-527, 2000. 